\title{
Performance Control of Positive-Working Electron Beam Resists by Copolymerization and Blending
}

\author{
Kazuyuki Sugita, Nobuo Ueno, Michimasa Funabashi, Yasuyuki YoshidA, \\ Yasunori DoI, Shiro NAGATA, ${ }^{*}$ and Shigeru SASAKI* \\ Department of Image Science and Technology, Faculty of Engineering, \\ - Chiba University, Yayoi-cho, Chiba 260, Japan \\ * Central Research Laboratories, Kuraray Co., Ltd., \\ Aoeyama, Sakazu, Kurashiki, Okayama 710, Japan
}

(Received February 6,.1985)

\begin{abstract}
EB exposure characteristics, such as sensitivity and contrast, and durability against oxygen plasma were measured with linear copolymers and polymer blends of various composition, which were prepared from $\alpha$-methylstyrene [MSt] and methyl methacrylate [MMA]. Moreover, new developers were examined for these polymers, since sensitivity and contrast of the positive-working resist system depend largely on dissolution kinetics concerning each combination of the resist polymer and the developer. Methyl isobutyl ketone and isoamyl acetate were used as the developer, though they were developers of excessive dissolving power for PMMA and /or PMSt homopolymers. The copolymers containing $30-50 \mathrm{~mol} \%$ of MSt were as durable as PMSt homopolymer against oxygen plasma and had higher contrast than PMMA. The blend had dryetching durability as large as the copolymer of the same composition, and showed considerably high contrast, while the copolymer had higher sensitivity than the blend. The blends containing $21 \mathrm{~mol} \%$ or less of MSt monomer units were much more durable than PMMA and of contrast as high as PMMA, but less sensitive than PMMA.

KEY WORDS Sensitivity / Contrast / Durability / Oxygen Plasma / Dry Etching / $\alpha$-Methylstyrene / Methyl Methacrylate / Composition / Developer /
\end{abstract}

As the dimensions of electronic devices shrink, the resists for microfabrication are required to have excellent performance such as i) higher contrast, ii) larger dry-etching durability, and iii) higher sensitivity. It is generally said from theoretical consideration and experimental results that positive-working resists are of high contrast. Recently, it has been found out that dry-etching durability and sensitivity are the two contradicting properties in positive-working electron resists; a durable resist such as poly(phenyl methacrylate) [PPhMA] has a low sensitivity, while a sensitive resist such as poly(butene-1 sulfone) [PBS] is not durable enough. ${ }^{1}$ This tendency was derived from the study on one-component resist systems composed of degradable linear homopolymers, and does not deny the future development of excellent resist systems which have all the characteristics i), ii), and iii), if the candidates to be investigated are extended toward multi-component, crosslinked polymer, and /or copolymer systems. For example, PPhMA was sensitized by copolymerizing with a small amount of crosslinkable monomer at the slight expense of its large dry-etching durability. ${ }^{2}$ The durability of poly(olefin sulfone) was extensively improved by blending with an aromatic resin at a great loss of high sensitivity, as was observed with the poly(2-methyl -1-pentene sulfone)-novolac system. $^{3}$ Sensitivity of poly(methyl methacrylate) was enhanced by copolymerization with a fragile monomer, e.g., methyl chloroac- 
rylate or ethyl cyanoacrylate, but there was no description of the effect on the dry-etching durability. ${ }^{4}$

The dry-etching durability against oxygen plasma of a negative copolymer resist, COP [poly(glycidyl methacrylate-co-ethyl acrylate)], is reported to be calculated by following the weight percent additivity based on the constituent monomer. ${ }^{5}$ However, it may be unreliable because the bent point on the etching ratetemperature plot appears at a different temperature for each resist polymer. ${ }^{6}$ At least it is doubtful that simple additivity is applicable to all the positive-working copolymer resists at any temperature.

In the case of crosslinked positive-working and crosslinkable negative-working resists, it is possible to predict the sensitivity by a theoretical treatment based on gel formation, if linear and crosslinked polymers are assumed to be soluble and insoluble, respectively. ${ }^{7,8}$ On the other hand, the sensitivity and the contrast of resist systems composed of linear polymers are determined experimentally under the most suitable developing conditions, viz., developer composition, temperature, developing period, etc. Since they depend mainly on the change of dissolution rate before and after EB exposure, dissolution kinetics concerning each combination of the resist polymer and the developer is essential to the EB exposure characteristics (lithographic sensitivity and contrast) as well as the intrinsic radiation sensitivity ( $G$-value for scission) of the polymer of interest. ${ }^{9,10}$ In other words, the finding of a new preferable developer for a known resist polymer is as significant as establishment of a new resist polymer of high performance to be processed with a conventional developer.

Among the three characteristics abovementioned, higher contrast and larger dryetching durability are the mosit indispensable to the microfabrication of electronic devices of shrinked dimensions, because slightly lower sensitivity can be suppressed at the expense of longer exposure time. In this study we em- ployed poly(methyl methacrylate) and $\operatorname{poly}(\alpha-$ methylstyrene), which are a typical resist of high contrast and a most dry-etching durable resist, respectively, and prepared various copolymers and polymer blends thereof. By changing the composition in the copolymer or the blend, EB exposure characteristics were measured, and at the same time durability against oxygen plasma was observed at various temperatures. Moreover, new developers were examined for these copolymers and blends, for sensitivity and the contrast may be further increased without decreasing the durability at all. If the composition control as well as the developer contrivance highly improves one of the characteristics with slight loosing, preferably without loosing, another advantage, it will provide a key to molecular design of an excellent resist polymer with balanced performance.

\section{EXPERIMENTAL}

\section{A. Preparation of Resist Polymers}

Poly $(\alpha$-methylstyrene) [abbreviated to PMSt, hereafter] was prepared by cationic polymerization in $\mathrm{CH}_{2} \mathrm{Cl}_{2}$ at $-78^{\circ} \mathrm{C}$ with $\mathrm{BF}_{3} \cdot \mathrm{OEt}_{2}$ as a catalyst. $\mathrm{Poly}(\alpha$-methylstyreneco-methyl methacrylate [PMSt-MMA] and poly(methyl methacrylate) homopolymer [PMMA-1] were prepared by emulsion polymerization at $80^{\circ} \mathrm{C}$ with $\mathrm{K}_{2} \mathrm{~S}_{2} \mathrm{O}_{8}$ as an initiator. These polymers were fractionated from a toluene or a tetrahydrofuran/methanol system. Besides the polymers prepared in-house, a commercial resist, OEBR-1000 (Tokyo Ohka Co., Ltd.) [PMMA-2] and a commercial polystyrene (Koso Kagaku Co., Ltd.) [PSt] were used for the control. The copolymerization ratio in moles was estimated by elemental analysis, the stereoregularity was by ${ }^{1} \mathrm{H}$ NMR spectrum, ${ }^{11-13} M_{n}$ and $M_{w}$ were by GPC, and $T_{\mathrm{g}}$ was by DSC. The results are summarized in Table I.

Polymer blends [PMSt + MMA], B-21, B-39, B-44, and B-80, were admixtures of PMSt P-35 
Performance Control of Positive-Working EB 'Resists

Table I. Summary of polymer data

\begin{tabular}{lccccc}
\hline Polymer (Abbrev.) & MSt: MMA & it:ht:st & $M_{w} \times 10^{-4}$ & $M_{w} / M_{n}$ & $T_{\mathrm{g}}$ \\
\hline PMMA-1 & $(0: 100)$ & $4.1: 36.9: 59.0^{\mathrm{a}}$ & 55.6 & 3.42 & $105^{\circ} \mathrm{C}$ \\
PMMA-2 & $(0: 100)$ & $8.9: 35.7: 55.4^{\mathrm{a}}$ & 57.0 & 4.54 & \\
& & & & & \\
PMSt-MMA (C-10) & $10: 90$ & $7.3: 39.4: 53.3^{\mathrm{b}}$ & 36.8 & 2.73 & 134 \\
PMSt-MMA (C-21) & $21: 79$ & $7.3: 39.4: 53.3^{\mathrm{b}}$ & 31.9 & 2.14 & 152 \\
PMSt-MMA (C-39) & $39: 61$ & $7.3: 39.4: 53.3^{\mathrm{b}}$ & 64.5 & 1.90 & 157 \\
PMSt-MMA (C-44) & $44: 56$ & $7.3: 39.4: 53.3^{\mathrm{b}}$ & 37.4 & 1.69 & 170 \\
& & & & & \\
PMSt (P-35) & $(100: 0)$ & $0: 8.3: 91.7^{\mathrm{c}}$ & 59.3 & 2.44 & 173 \\
PMSt (P-60) & $(100: 0)$ & & & & \\
PSt & - & & & & \\
\hline
\end{tabular}

a Tacticity obtained from $\alpha$-methyl proton resonance, see ref 11 .

b Cotacticity from methoxy proton resonance, see ref 12 .

c Tacticity from $\alpha$-methyl proton resonance, see ref 13 .

and PMSt-MMA C-10, the MSt contents of which were $21,39,44$, and $80 \mathrm{~mol} \%$, respectively. PMSt + MMA B-10 was a polymer blend of PMSt P-35 and PMMA-1, which contained $10 \mathrm{~mol} \%$ of MSt.

\section{B. Specimen Preparation and Thickness Measurement}

The resist film was prepared by spin-coating from the toluene solution on a thin copper layer evaporated onto a glass plate. It was prebaked at $180^{\circ} \mathrm{C}$ in an air-circulating oven for $20 \mathrm{~min}$. The phase separation of the blended resist film, as was reported on the PMPSnovolac system, ${ }^{3}$ was not observed under an optical microscope. For the study of EB exposure characteristics, the specimen was exposed in such a way as described next, developed by dipping without agitation in a developer kept at $25^{\circ} \mathrm{C}$, and postbaked at $140^{\circ} \mathrm{C}$ for $20 \mathrm{~min}$. When methyl isobutyl ketone was used as the developer, the specimen was rinsed with isopropanol. In order to measure dry-etching durability, the resist film was exposed to the oxygen plasma which was generated in the apparatus described in Section D. The developed or etched depth was measured with an interference microscope, Nikon Surface Finish Microscope, after evap- orating aluminum onto the surface of the specimen. The initial thickness of the resist film was measured in the same way after partial scratching.

\section{Electron Beam Exposure}

In Figure 1 the EB exposure system is shown schematically. The system consists of an electron gun with a deflector, a rotatable sample holder and a vacuum system. The electrons emitted from a filament were accelerated at $4 \mathrm{kV}$ and swept spatially by applying ac potential $(50 \mathrm{~Hz})$ to the deflector in order to realize uniform irradiation to a wide area of the resist film (flood exposure). The resist was exposed to the uniform EB flux through an aperture of $2.0 \mathrm{~mm}$ diameter and a mask of stainless-steel mesh (light transmittance, 36\%; opening, $0.15 \mathrm{~mm} \times 0.15 \mathrm{~mm}$ square). In this way, the mesh pattern was transferred to the resist after appropriate development. The depth, which was the difference of the film thickness between the exposed and the unexposed areas after development, was measured as described in Section B. After exposure to varying dose, the depth was plotted against the logarithm of dose to get the characteristic curve. Prior to the EB exposure of resists, the incident EB current, after passing through the aperture and 


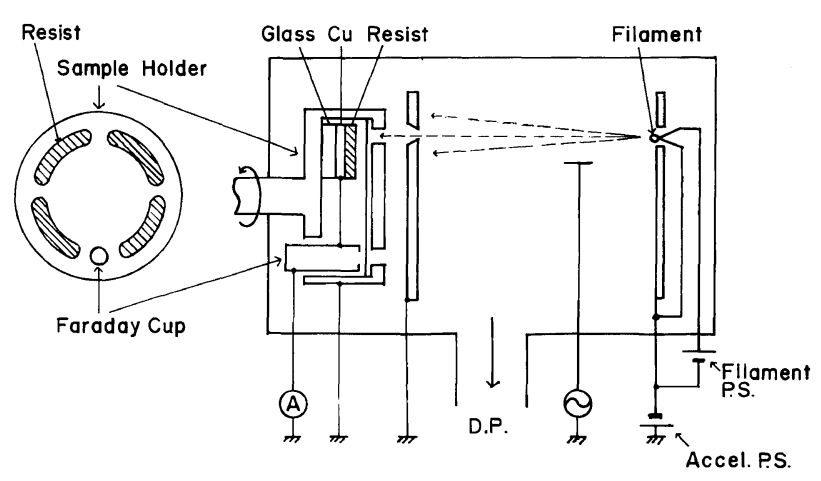

Figure 1. Schematic diagram of EB exposure system.

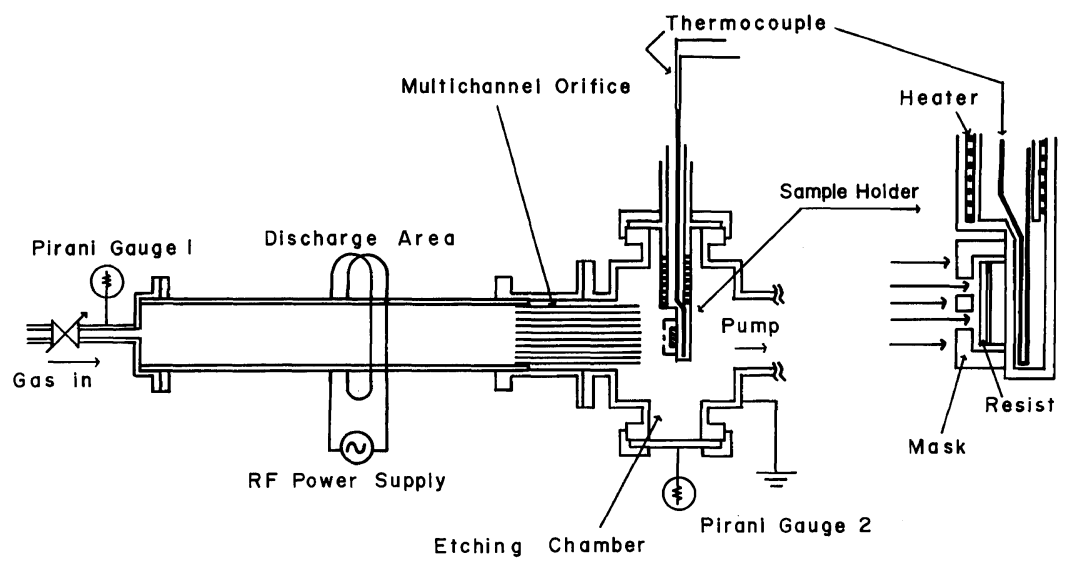

Figure 2. Experimental set-up of dry etching apparatus.

the mask, was measured with a Faraday cup mounted on the sample holder. The stability of the EB current was checked during the exposure by monitoring the electron current transmitted to the copper underlayer. All EB exposure experiments were carried out at room temperature (R.T.) and at a pressure less than $2 \times 10^{-5}$ torr. The exposure conditions are summarized in Table II.

\section{Dry Etching of Resists}

The etching system is shown in Figure 2. Etching of resists was achieved in the stainlesssteel chamber separated from the glow discharge area by the multichannel orifice (MCO) which was a bundle of glass tubings of $3 \mathrm{~mm}$ inner-diameter and $100 \mathrm{~mm}$ long. The oxygen gas was introduced into the chamber, discharged by a $13.56 \mathrm{MHz}$ rf-power supply, and excited species were transported into the etching chamber through $\mathrm{MCO}$ at a pressure of 0.03 torr, which was measured directly with Pirani Gauge 2. The resist kept at various temperatures was exposed to the excited oxygen stream through a copper mask with 6 small holes (the total area of the holes was $0.2 \mathrm{~cm}^{2}$ ). The deviation from the temperature indicated by the thermocouple in Figure 2 was checked with another thermocouple which was attached to the resist surface, and used for the calibration of resist temperature. The loading effects were not found for the etching area $\leqq 0.2 \mathrm{~cm}^{2}$ under a $300 \mathrm{~W}$ discharge condition. The contribution of oxygen ions to the etching 
Table II. Conditions of electron beam exposure and dry etching

\begin{tabular}{|c|c|c|}
\hline & EB exposure & Dry etching \\
\hline Gas & - & Oxygen \\
\hline Pressure & $<2 \times 10^{-5}$ Torr & 0.03 Torr \\
\hline Temperature & R.T. & R.T. $-180^{\circ} \mathrm{C}$ \\
\hline Resist thickness & $3500-4500 \AA$ & $3000-8000 \AA$ \\
\hline Energy/power & $4 \mathrm{keV}$ & $\begin{array}{l}\text { Forward } 300 \mathrm{~W} \\
\text { Reverse } \leqq 30 \mathrm{~W}\end{array} \quad(13.56 \mathrm{MHz})$ \\
\hline Current density & $8.85 \times 10^{-7} \mathrm{~A} \mathrm{~cm}^{-2}$ & - \\
\hline Sample potential & - & 0 \\
\hline Type & $\begin{array}{l}\text { Flood exposure through } \\
\text { stainless-steel mesh }\end{array}$ & $\begin{array}{l}\text { Etching chamber separated } \\
\text { from the discharge area }\end{array}$ \\
\hline
\end{tabular}

was checked by changing the potential $\left(V_{\mathrm{s}}\right)$ of the sample holder, and found to be small enough in comparison with that by neutral species for $V_{\mathrm{s}} \geqq 0 \mathrm{~V}$. The etching conditions are also summarized in Table II.

The present set-up eliminated the problems of etch-rate acceleration caused by temperature rise, isotropic etching and various damage of resists which are generally found in dryetching experiments with usual barrel and parallel-plate type reactors.

\section{RESULTS AND DISCUSSION}

\section{A. EB Exposure Characteristics}

1) Determination of Sensitivity and Contrast

A series of characteristic curves were obtained from the resist films of different thickness. For example as shown in Figure 3a, PMMA films of 3500,4000 , and $4500 \AA$ thick gave curves O-O'-A-A', O-O'-B-B', and O-O'-

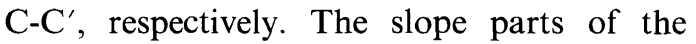
characteristic curves $\left(\mathrm{O}^{\prime}-\mathrm{A}, \mathrm{O}^{\prime}-\mathrm{B}\right.$, and $\left.\mathrm{O}^{\prime}-\mathrm{C}\right)$, which were approximately straight lines coincided with each other, though accompanied with a tail curve of $\mathrm{O}-\mathrm{O}^{\prime}$. The critical dose, which was required to just remove the last trace of the resist film in the exposed area by development, increased from $\mathrm{A}$ to $\mathrm{B}$, and from $B$ to $C$, as the film became thicker. Therefore, if the sensitivity is defined by the critical dose as is generally done, ${ }^{14}$ it decreases with an increase of thickness. In this study

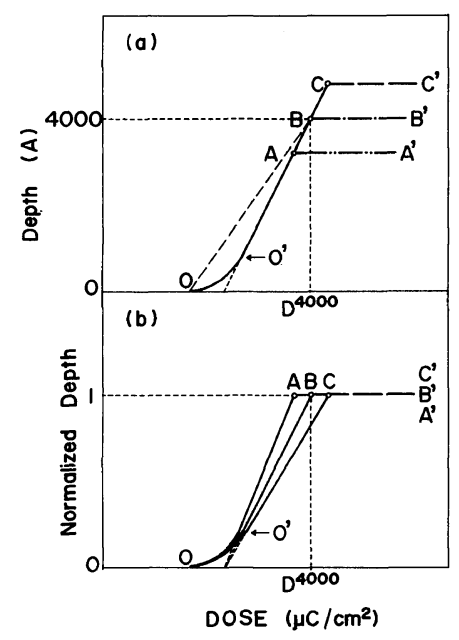

Figure 3. Characteristic curves (upper) and normalized characteristic curves (under) observed with PMMA films of different thickness.

$4000 \AA$ was employed as a standard thickness, considering the Grun range which depended mainly on the exposure parameters. ${ }^{10}$ The sensitivity was measured with the resist film of $4000 \AA$ thick (strictly speaking, the remaining film in the unexposed area was $4000 \AA$ thick), and is abbreviated as $D^{4000}$. When the film was thicker or thinner than $4000 \AA$, sensitivity was calibrated by assuming the relationship which is indicated in Figure 3a.

The contrast, $\gamma$, was determined, as usual, from the slope of the normalized characteristic curve, in which the depth was normalized to the remaining thickness in the unexposed area, 
and plotted against the logarithm of the dose. In this case $\gamma$ should be calculated from the curve which was also measured with the resist film of $4000 \AA$ thick, since the value from a thinner film is larger, and vice varsa (see Figure $3 b)$. When the depth measurement is performed with a thinner or thicker film, it is necessary that the characteristic curve should be first calibrated to that of the film of standard thickness before calculating the contrast therefrom. In addition, $\gamma^{\prime}$ was calculated from the slope of a straight line directly connecting $\mathrm{O}$ with $\mathrm{B}$ in Figure $3 \mathrm{a}$ in order to compare it with the value which was obtained from the S-shaped characteristic curve to be mentioned next. When the tail was negligible, $\gamma^{\prime}$ was substantially equal to $\gamma$, but the former was generally smaller than the latter in the case of characteristic curve accompanied with some tail.

Similar experiments on the PMSt brought about a series of $\mathrm{S}$-shaped characteristic curves as shown in Figure 4, where points A, B, and C indicate the above-mentioned critical dose. The depth showed saturation with an increase of exposure dose, which meant a larger dose was required for solubilizing the resist polymer neighboring with the substrate. It was obscure why the dissolution kinetics of the PMSt system was so different from that of PMMAs. The sensitivity and the contrast could not be determined by the same method as before. From curve $\mathrm{O}-\mathrm{O}^{\prime}-\mathrm{B}^{-} \mathrm{B}^{\prime}$ measured with the film of just $4000 \AA$ thick, $D^{4000}$ was obtained from the critical dose (point B) which was required to remove the resist film as defined with PMMA. S-shaped curves, $\mathrm{O}-\mathrm{O}^{\prime}-\mathrm{A}-\mathrm{A}^{\prime}$ and $\mathrm{O}-\mathrm{O}^{\prime}-\mathrm{C}-\mathrm{C}^{\prime}$, were observed with thinner and thicker films, respectively. Since points A, B, and C were found to be situated on a straight line which was parallel to the straight part in the middle of the S-shaped curve, point $\mathrm{B}$ was determined graphically by shifting point $\mathrm{A}$ or $\mathrm{C}$ along the line. The contrast, $\gamma^{\prime}$, was calculated from the slope of another straight line di-

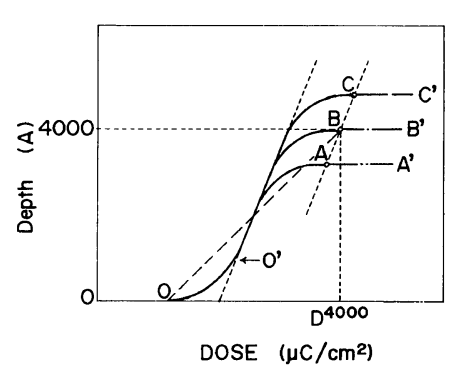

Figure 4. Characteristic curves observed with PMSt films of different thickness.

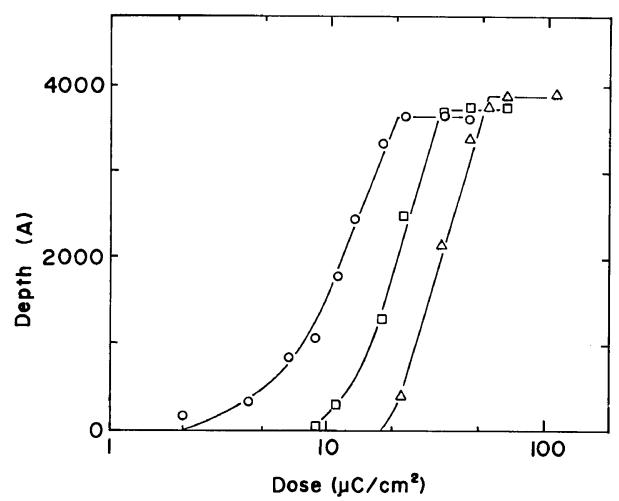

Figure 5. Effect of developer on the characteristics of PMMA: $\bigcirc$, MIBK; $\square$, IAA; $\triangle$, MIBK (3)+IPA (7).

rectly connecting $\mathrm{O}$ with $\mathrm{B}$. When the film was thinner or thicker than $4000 \AA$, the characteristic curve was first calibrated to that with $4000 \AA$ thick (curve $\mathrm{O}-\mathrm{O}^{\prime}-\mathrm{B}-\mathrm{B}^{\prime}$ ) before the contrast calculation.

\section{2) Effect of Developer}

The PMMA-2 films around $4000 \AA$ thick were exposed and developed for $90 \mathrm{~s}$ with a mixed solvent of methyl isobutyl ketone [MIBK] and isopropanol [IPA] of 3:7 by volume $[\mathrm{MIBK}(3)+\operatorname{IPA}(7)]$, isoamyl acetate [IAA], or neat MIBK. Decreases of thickness of the unexposed area during development using the above-mentioned three type of developers were about 100,250 , and $300 \AA$, respectively. The characteristic curves are shown in Figure 5. All curves were of the type in Figure 3a. The sensitivity was the highest when developed by MIBK, and decreased in the order of MIBK $>$ IAA $>\operatorname{MIBK}(3)+$ IPA 


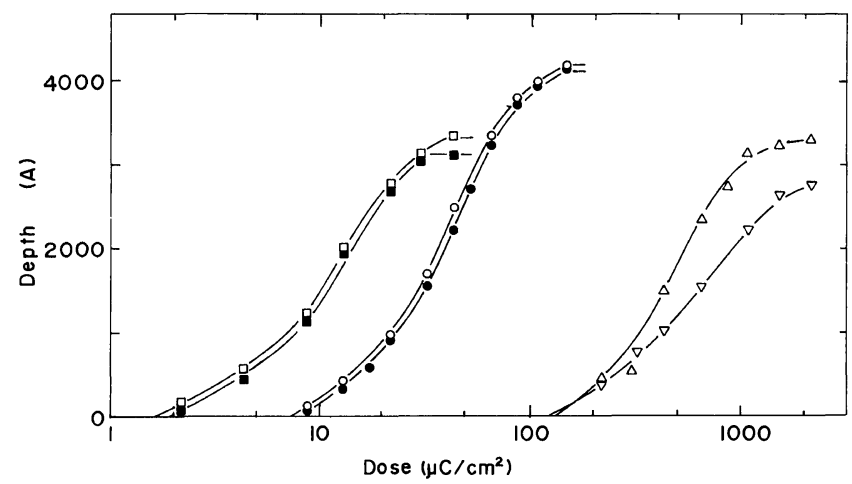

Figure 6. Effects of developer and molecular weight on the characteristics of PMSt: P-35 developed with: O, MIBK; $\square$, IAA; $\triangle$, MIBK (6)+IPA (4); $\nabla, \mathrm{Bz}(3)+\mathrm{MeOH}(7)$ : P-60 developed with: $\bigcirc$, MIBK; IAA.

(7), while $\gamma$ was the largest when IAA was used for the developer.

EB exposure characteristics of PMSt P-35 were also studied by changing the developing conditions: i.e., with MIBK for $90 \mathrm{~s}$, with IAA for $90 \mathrm{~s}$, with $\operatorname{MIBK}(6)+\operatorname{IPA}(4)$ for $5 \mathrm{~min}$, and with a mixed solvent of benzene [Bz] and methanol $[\mathrm{MeOH}]$ of $3: 7$ by volume $[\mathrm{Bz}(3)+\mathrm{MeOH}(7)]$ for $5 \mathrm{~min}$. The characteristic curves thus obtained are shown in Figure 6. The depth developed under the last two conditions showed saturation as an increase of exposure dose at a smaller value than the remaining thickness in the unexposed area. That is, the resist film in the exposed area could not be completely dissolved away by the development. The sensitivity was the highest with IAA, but this solvent was found inadequate as the developer for PMSt since the decrease of thickness was $750 \AA$, which corresponded to $20 \%$ of the initial thickness. The sensitivity was the second highest with MIBK, and the decrease of thickness was $50 \AA$. The contrast, $\gamma^{\prime}$, was found to be less than 1 in both cases, so this resist was not suitable for the high resolution work, how durable it may be.

PMSt-MMA C-39 was examined under the same developing conditions as PMSt P-35, but the results obtained with the copolymer were quite different from those of a constituent homopolymer, PMSt (compare Figure 7 with

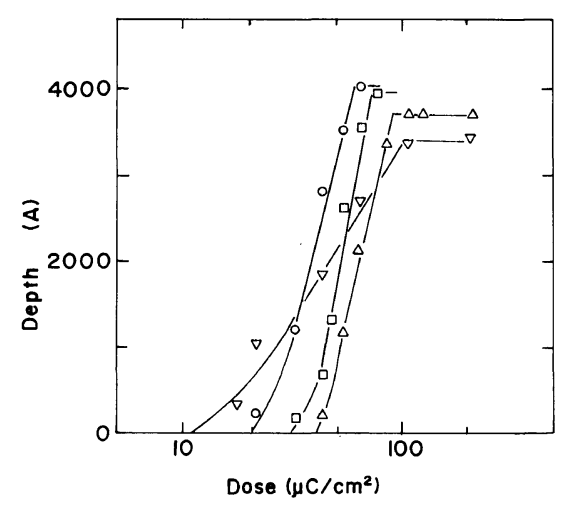

Figure 7. Effect of developer on the characteristics of PMSt-MMA: $\bigcirc, \quad$ MIBK; $\square, \quad$ IAA; $\triangle$, $\operatorname{MIBK}(6)+\mathrm{IPA}(4) ; \nabla, \mathrm{Bz}(3)+\mathrm{MeOH}(7)$.

Figure 6). The resist films were successfully developed in all cases, and the characteristic curves were of the type shown in Figure 3a. The decrease of thickness was about $100 \AA$ for IAA and less than $100 \AA$ for MIBK. The sensitivity was the highest with MIBK, and decreased in the order of $\mathrm{MIBK}>\mathrm{IAA}>$ $\operatorname{MIBK}(6)+\operatorname{IPA}(4)>\mathrm{Bz}(3)+\mathrm{MeOH}(7)$, while $\gamma$ was the highest with IAA and decreased in the order of IAA $>\operatorname{MIBK}(6)+\operatorname{IPA}(4)>$ $\mathrm{MIBK} \gg \mathrm{Bz}(3)+\mathrm{MeOH}(7)$.

From the results above-mentioned, it was decided to use MIBK and IAA as the developers for the present resist system composed of the copolymer or the polymer blend. $D^{4000}$ and $\gamma$ (or $\gamma^{\prime}$ ), which were measured by 
using MIBK or IAA as the developer, are indicated in Table III for comparison with the values of other copolymers and blends to be measured afterwards.

\section{3) Effect of Molecular Weight and Stereo- regularity}

PMSt homopolymers of dfferent molecular weight, P-35 and P-60, were investigated and the characteristic curves were found to be identical within an experimental error whether the developer used was MIBK or IAA (see Figure 6). It is established by Greeneich that for a given contrast level a larger molecular weight reduces the required dose (namely enhances the sensitivity), and that a high molecular weight polymer is preferred in order to obtain a high contrast for a given dose at the expense of longer development periods. ${ }^{9,10}$ However, as long as the resist films were developed for the same developing periods, the difference in molecular weight ranging from 350,000 to 600,000 had no effect on the sensitivity and the contrast.

Since the copolymers had quite similar tacticity to that of the PMMAs as shown in Table I, it was considered that the effect of stereoregularity was hardly involved in the difference of their EB exposure characteristic results. On the other hand, the PMSt was predominantly syndiotactic, and the stereoregularity was fairly different from those of the PMMAs and the copolymer PMSt-MMAs. Sharma et al. reported that isotactic, heterotactic and syndiotactic PMMAs had sensitivities of 20,60 and $200 \mu \mathrm{C} \mathrm{cm}{ }^{-2}$, respectively, when developed with MIBK[4]+IPA[6] for $60 \mathrm{s.}^{15}$ The sensitivity of a PMMA, the tacticity of which is it: ht: $s t=8.9: 35.7: 55.4$, is calculated to be $134 \mu \mathrm{C} \mathrm{cm}^{-2}$ from the above-mentioned sensitivity data. Similarly, another PMMA, which has the same tacticity as the PMSt (it: ht: $\mathrm{st}=0: 8.3: 91.7)$, is estimated to be $188 \mu \mathrm{C}$ $\mathrm{cm}^{-2}$. The former is 1.4 times as sensitive as the latter. If the correlation holds to both the PMMA and the PMSt-MMAs developed under the conditions studied here, $D^{4000}$

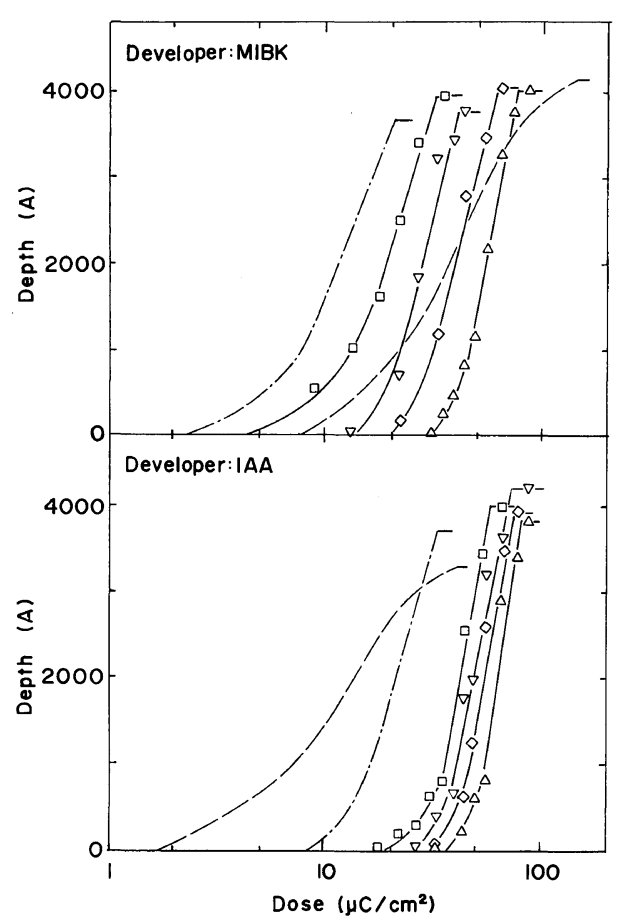

Figure 8. Effect of copolymerization ratio on the characteristics: - - PMMA; $\square$, C-10; $\nabla$, C-21; $\diamond$, C-39; $\triangle$, C-44; ----, P-35.

Table III. Sensitivity and contrast

\begin{tabular}{|c|c|c|c|c|c|c|}
\hline \multirow{3}{*}{ Polymer } & \multicolumn{6}{|c|}{ Developer } \\
\hline & \multicolumn{3}{|c|}{ MIBK } & \multicolumn{3}{|c|}{ IAA } \\
\hline & $D^{4000}$ & $\gamma$ & $\left(\gamma^{\prime}\right)$ & $D^{4000}$ & $\gamma$ & $\left(\gamma^{\prime}\right)$ \\
\hline PMMA-2 & 25 & 1.8 & $(0.9)$ & 35 & 1.9 & (1.6) \\
\hline \multicolumn{7}{|c|}{ PMSt-MMA } \\
\hline (C-10) & 35 & 1.8 & (1.4) & 60 & 3.8 & (1.9) \\
\hline (C-21) & 45 & 2.5 & $(1.8)$ & 70 & 4.2 & (2.4) \\
\hline (C-39) & 65 & 2.4 & (2.0) & 80 & 4.2 & $(2.5)$ \\
\hline (C-44) & 70 & 2.8 & $(2.2)$ & 90 & 3.9 & (2.3) \\
\hline \multicolumn{7}{|c|}{ PMSt + MMA } \\
\hline (B-10) & 70 & & (1.3) & 90 & & (1.7) \\
\hline (B-21) & 85 & & (1.6) & 110 & & $(2.0)$ \\
\hline (B-39) & 150 & & (1.5) & 160 & & (1.7) \\
\hline (B-44) & 140 & & (1.6) & 155 & & (1.7) \\
\hline (B-80) & 160 & & (1.3) & 140 & & $(1.2)$ \\
\hline \multicolumn{7}{|l|}{ PMSt } \\
\hline (P-35) & 135 & & $(0.8)$ & 65 & & $(0.6)$ \\
\hline (P-60) & 140 & & $(0.8)$ & 75 & & $(0.6)$ \\
\hline
\end{tabular}


of the PMMA and the PMSt-MMA listed in Table III should be multiplied by 1.4 to be compared with those of the PMSt.Then, it is found that the effect of stereoregularity on the sensitivity is much smaller than that of the developer (discussed in Section A-2) or the polymer composition (to be discussed in Sections A-4 and A-5).

\section{4) Effect of Copolymerization Ratio}

The characteristic curves of four copolymers with different MSt contents, PMSt-MMA C10, C-21, C-39, and C-44, were measured by using MIBK and IAA as the developer, and the results are indicated in Figure 8. All the curves were of the type in Figure 3a, which suggested high contrast. Actually, as is summarized in Table III and Figure 10, the contrast, $\gamma$ or $\gamma^{\prime}$, of the copolymers was much higher than that of PMMA. Especially when they were developed with IAA, the copolymers showed a very high contrast. This may be ascribed to the preferable dissolution kinetics of PMSt-MMA/MIBK and PMSt-MMA/ IAA systems, which must be quite different from those of PMSt and PMMA homopolymers.

As is seen in Figure 11 in which $D^{4000}$ is plotted against the MSt content, the sensitivity of the copolymer decreased monotonously as the MSt content increased. The mechanism of radiolysis proposed for $\mathrm{PMMA}$ at $25^{\circ} \mathrm{C}$ is the initial cleavage of $\mathrm{C}-\mathrm{C}$ bond between the main chain carbon and carbonyl group, followed by the rearrangement through beta scission to cleave the main chain.,16,17 The Gs-value is reported to be $1.3^{4} \sim 2.3 .^{6}$ Degradation of PMSt at $25^{\circ} \mathrm{C}$ under vacuum is explained as a random breaking of skeletal chain bond accompanied by depropagation to split off about 100 monomer units, ${ }^{18}$ and the determined Gsvalue is $0.23^{6} \sim 0.25 .^{18}$ Since the PMSt-MMA copolymers, which were prepared by radical polymerization, contained MSt units isolated from each other in the copolymer chain as was deduced theoretically from the copolymerization reactivity ratio of $\mathrm{MSt}$ and confirmed by ${ }^{1} \mathrm{H}$ NMR spectrum, the depolymerization did not contribute to the decrease of molecular weight on EB exposure. The intrinsic radiation sensitivity of PMSt-MMA is ascribed to the bond scissions between MMA-MSt units as well as those between MMA-MMA units in the main chain. The lower scission rate of the former bond than that of the latter bond may have brought about the sensitivity results above-noted.

\section{5) Effect of Blending Ratio}

Five polymer blends with different MSt content, PMSt + MMA B-10, B-21, B-39, B44, and B-80, were studied similarly. The results are in Figure 9. The characteristic curves were S-shaped, though they were not so curved as was that of PMSt. It was found that the blends were inferior to the copolymers of the same composition in the sensitivity and the contrast (see Table III and Figures 10 and 11). The contrast of the blend was a little higher

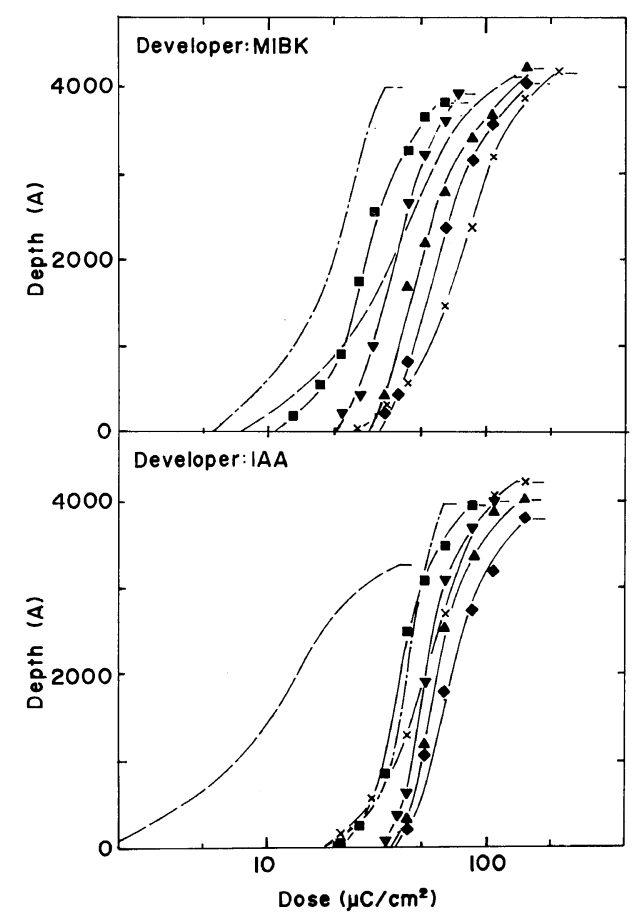

Figure 9. Effect of blending ratio on the characteristics: - - - C-10; $\mathbf{\square}, \mathrm{B}-10$; $\boldsymbol{\nabla}, \mathrm{B}-21$; $\bullet, \mathrm{B}-39 ; \mathbf{\Delta}, \mathrm{B}-44$; $\times, \mathrm{B}-80 ;----, \mathrm{P}-35$. 


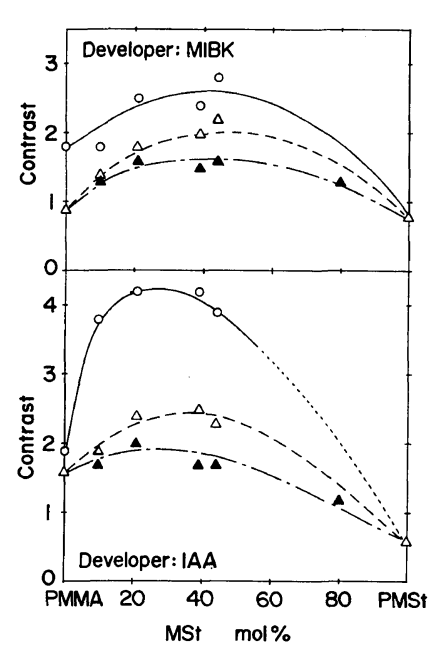

Figure 10. Effect of composition on the contrast: $\bigcirc, \gamma$ of copolymer; $\triangle, \gamma^{\prime}$ of copolymer; $\boldsymbol{\Delta}, \gamma^{\prime}$ of blend.

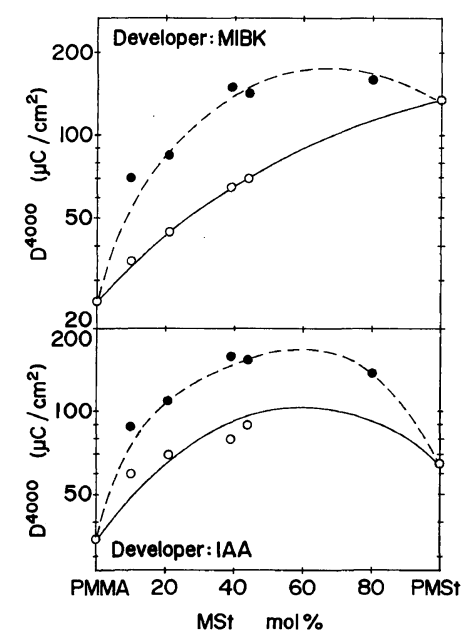

Figure 11. Effect of composition on the sensitivity: $O$, copolymer; $\boldsymbol{O}$, blend.

than $\gamma^{\prime}$ of PMMA, the tail being smaller in the lower dose region. The sensitivities of PMSt + MMA B-10 and B-21, which were measured by using the MIBK developer, were higher than that of PMSt, but lower than the mol- or weight-averaged value of the two constituent polymers. Blends with higher MSt content, PMSt + MMA B-39, B-44, and B-80, which contained $35.5,41.3$, and $80.2 \mathrm{wt} \%$ of PMSt P-35, respectively, were less sensitive than either of the constituent polymers, PMSt and PMSt-MMA. The reason is not clear at present. The excitation probability in the radiation process is not decreased by blending, since van der Waals' interaction scarcely changes the electronic states of polymer molecules. ${ }^{19}$ As a tentative explanation, it may be assumed that molecular packing in the film and dissolution kinetics of the polymer blend are less favorable than those of the constituent polymers or the copolymers, and, therefore, larger dose was required to remove the resist film completely.

\section{B. Durability against Oxygen Plasma}

\section{1) Measurement of Dry Etching Rate}

The depth etched by the oxygen plasma was plotted against the exposure time, and a linear relationship was found between them, as long as the substrate temperature was kept constant. The etch rate was obtained as the slope of the plot and was confirmed to be independent of the initial thickness of the resist film. The depth increased at a constant rate until it attained the initial thickness and the resist film was removed completely. Then it was considered that the dry etching or the thickness reduction proceeded through the chemical reaction, which took place at the film surface, and the rate did not depend on the residual volume of resist polymer.

Harada estimated molecular weight and its distribution in the cross section of the resist film from GPC data, and deduced that the chain scission leading to a decrease of molecular weight occurred not only at the surface but also in the deep layer of the film..$^{20}$ If the thickness reduction is caused by the reaction occurring in the bulk of resist film, the thickness will not decrease linearly with an increase of the exposure time. As was observed with the UV light from the deuterium discharge lamp by the present authors, far UV light, which was emitted from the oxygen plasma, may also contribute to the thickness reduction. ${ }^{21,22}$ In that case the thickness decreased linearly as an increase of the exposure time at first, but it 


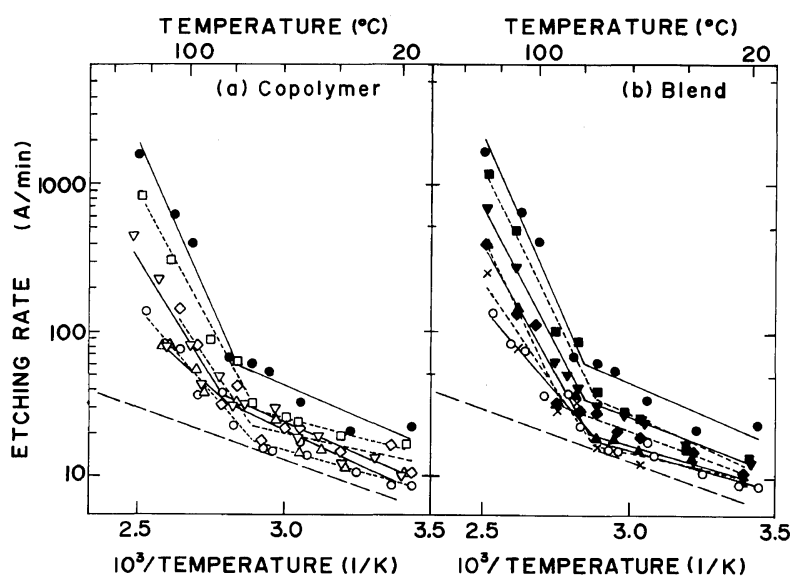

Figure 12. Arrhenius plot of dry etching rate: $\bullet$ PMMA; $\square, \mathrm{C}-10 ; \nabla, \mathrm{C}-21 ; \diamond, \mathrm{C}-39 ; \triangle, \mathrm{C}-44 ; \mathbf{\square}, \mathrm{B}-$ $10 ; \boldsymbol{\nabla}, \mathrm{B}-21 ; \diamond, \mathrm{B}-39 ; \mathbf{\Delta}, \mathrm{B}-44 ; \times, \mathrm{B}-80 ; \bigcirc, \mathrm{P}-35 ;----$, PSt.

Table IV. Rate and activation energy of dry etching

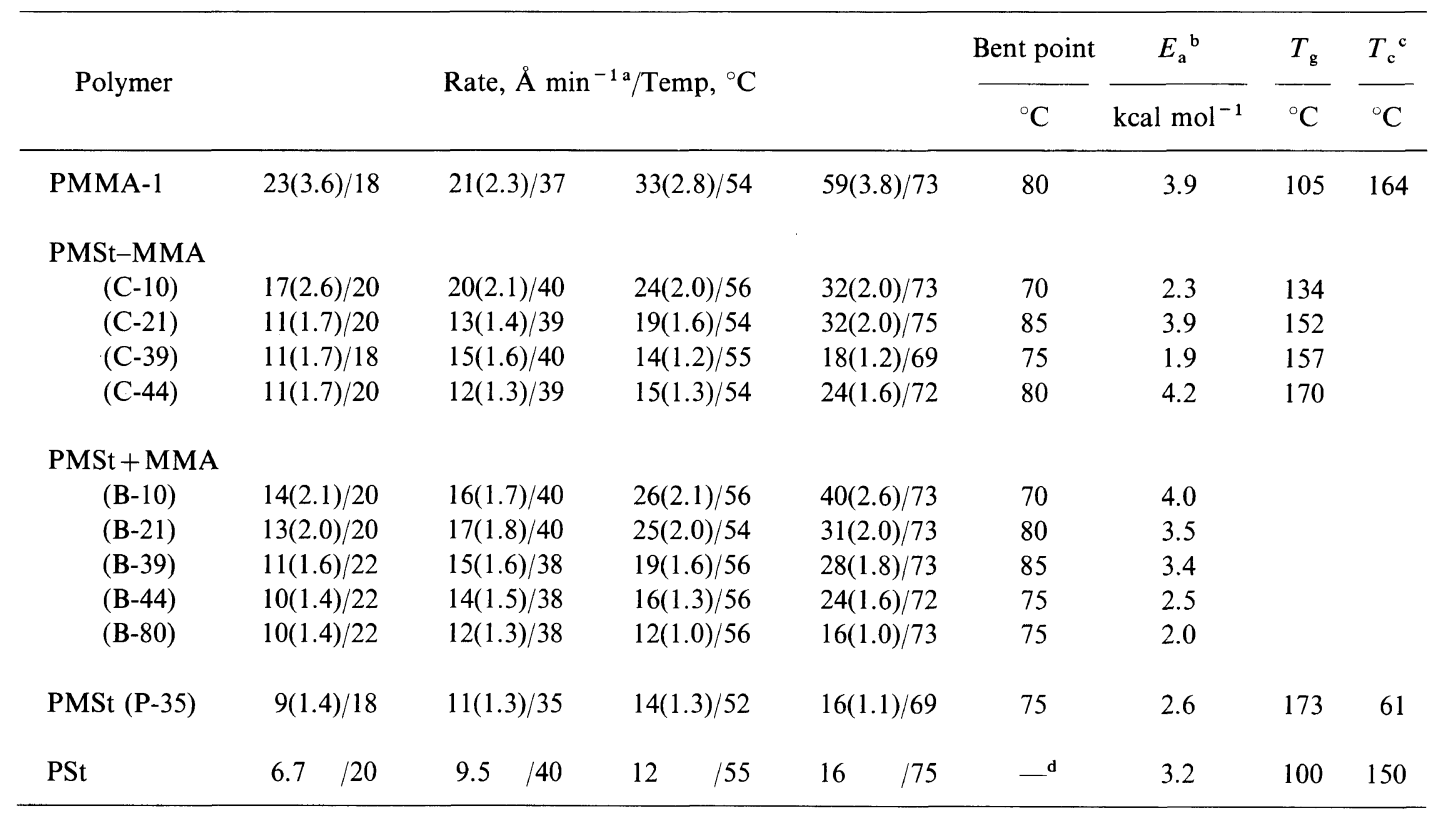

${ }^{a}$ Figures in parentheses: relative etching rate to PSt.

b Activation energy below bent point.

c J. Brandrup and E. H. Immergut, "Polymer Handbook," 2nd ed, John Wiley \& Sons, 1975, pp II-437-439.

d The bent point was not observed below $160^{\circ} \mathrm{C}$.

decreased proportionally to the logarithm of the exposure time as the resist film became thinner. ${ }^{23}$ Both results suggest that the dry etching by the oxygen plasma is mainly ascribed to the surface reaction which is different from the chain scission or the reaction with UV-etching.

The durability against oxygen plasma was estimated by the etch rate; that is, the low etch rate means large durability and vice versa. 


\section{2) Temperature Dependence of Dry Etching Rate}

The etch rate was measured at various temperatures and the dependence was shown by an Arrhenius plot. Some of the results observed with the copolymers and the polymer blends, together with their homopolymers and polystyrene as a control, are indicated in Figure 12 and Table IV. The etch rate was accelerated abruptly above $70-85^{\circ} \mathrm{C}$, where the bent point was observed. The bent point is compared with glass transition temperature, $T_{\mathrm{g}}$, and ceiling temperature, $T_{\mathrm{c}}$, in Table IV. Activation energy of the etching reaction was calculated from the slope below the bent point and is also shown in Table IV.

It was considered by Harada that the bend of Arrhenius plots was caused by the accelerated contribution of depropagation, which followed the chain scission, above the bent point. ${ }^{20}$ Since the bent point does not coincide with $T_{\mathrm{c}}$ of three homopolymers in Table IV, it is reasonable that the depropagation is not merely the depolymerization to form monomers. He speculated the bent point was a critical temperature and was associated with glass transition temperature at which molecular mobility of polymers abruptly increased. The bent point was observed about $20^{\circ} \mathrm{C}$ below $T_{\mathrm{g}}$ of non-halogenated poly(alkyl methacrylate)s, but the correlation between the bent point and $T_{\mathrm{g}}$ did not hold in the case of poly(aromatic methacrylate)s, halogenated polymethacrylates, poly(methyl isopropenyl ketone), and PMSt. ${ }^{6}$ The correlation was not observed for the current copolymer systems, either. Quantum yield for the unimolecular chain scission of solid polymers, which is governed by mobility of polymer segments to form a special transition state (e.g., Norrish Type II reaction), is known to increase above $T_{\mathrm{g}}$ rapidly to the same value as that obtained in solution. ${ }^{24}$ Though the present etching reaction may have any relation to the local motion of side chains, it is doubtful that the reaction is controlled by long-range mobility

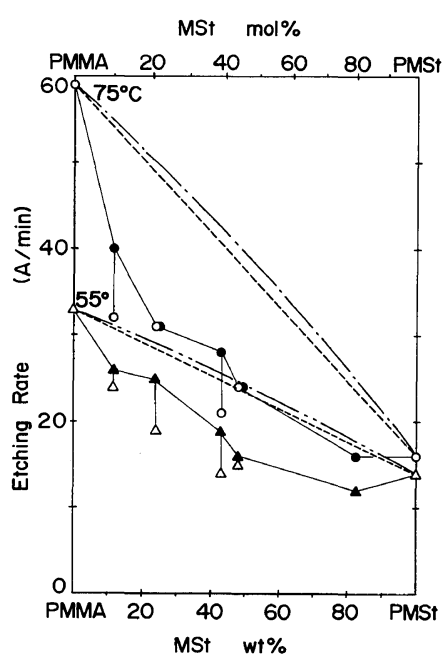

Figure 13. Effect of composition on the dry etching rate: $\bigcirc, \triangle$, copolymer; $\boldsymbol{O}, \boldsymbol{\Delta}$, blend. Broken and chain lines indicate weight- and mol-percent additivities, respectively.

of polymer segments.

3) Effects of Copolymerization and Blending Ratio

As seen in Figure 12 and Table IV, PMSt below $75^{\circ} \mathrm{C}$ was as durable as PSt, a typical negative-working polymer. On the contrary, it was found that the durability of PMMA was much smaller than a half of that of PSt at room temperature and decreased steadily with raise of temperature even below the bent point on account of its larger activation energy. The copolymers showed fairy large durability: much larger than PMMA and smaller than PMSt. The polymer blends were of moderate durability, but slightly less durable than the copolymers of the same composition (compare Figure 12b (right) with Figure 12a (left)).

Then, the etch rates at $55^{\circ} \mathrm{C}\left(52-56^{\circ} \mathrm{C}\right)$ and $75^{\circ} \mathrm{C}\left(72-75^{\circ} \mathrm{C}\right)$ were plotted against the MSt content in weight and in mol, and they are shown in Figure 13. It is clearly shown that the durability of the copolymer and the blend is much larger than that calculated by following the weight-percent or mol-percent additivity based on the constituent monomer unit. Namely, it is possible to enhance the dry- 
etching durability of PMMA by copolymerizing MSt or blending PMSt in small quantities. It is worth while to point out that the copolymers and the blends with $39 \mathrm{~mol} \%$ or more of the MSt content were as durable as PMSt homopolymer and about $0.6-0.8$ times as durable as PSt below the bent point. Even the copolymer and the blend containing $21 \mathrm{~mol} \%$ of MSt monomer units showed considerably large durability.

\section{CONCLUSION}

Copolymerization with $\alpha$-methylstyrene highly enhanced both dry-etching durability and contrast of PMMA at the slight expence of its sensitivity. The enhancement of the durability and the contrast was much greater than those anticipated on the basis of the literature which have been disclosed so far. Copolymers of MMA and MSt containing $30-50 \mathrm{~mol}^{\circ} \%$ of MSt were remarkably durable positiveworking resists of high contrast in the temperature.range below $70^{\circ} \mathrm{C}$ of their bent points. Blending of PMSt improved the durability of PMMA at a considerable loss of sensitivity, so blending ratio should be kept low. The contrast of PMMA was kept high, or rather improved, by blending with a minor amount of PMSt. Polymer blends composed of PMMA or PMSt-MMA and PMSt with $21 \mathrm{~mol} \%$ or less of MSt monomer units were durable positive-working resists of comparatively high contrast, but the sensitivity was lower than that of PMMA. As the sensitivity and the contrast, which were measured by using MIBK or IAA as the developer in this study, depended on the dissolution kinetics concerning each combination of the resist polymer and the developer, they might be further improved if a more suitable developer is found.

\section{REFERENCES}

1. T. Tamamura, S. Imamura, and S. Sugawara,
"Polymers in Electronics," ACS Symposium Series 242, T. Davidson Ed., The American Chemical Society, Washington, D. C., 1984, pp 103-118.

2. K. Harada, O. Kogure, and K. Murase, IEEE Trans. Elec. Dev., ED-29, 518 (1982).

3. M. J. Bowden, L. F. Thompson, S. R. Fahrenholtz, and E. M. Doerries, J. Electrochem. Soc., 128, 1304 (1981).

4. C. G. Willson, "Introduction to Microlithography," ACS Symposium Series 219, L. F. Thompson, C. G. Willson and M. J. Bowden Ed., The American Chemical Society, Washington, D. C., 1983, pp 123-126.

5. G. N. Taylor and T. M. Wolf, Polym. Eng. Sci., 20, 1087 (1980).

6. K. Harada, J. Appl. Polym. Sci., 26, 3395 (1981).

7. M. Suzuki and Y. Ohnishi, J. Electrochem. Soc., 129, 402 (1982).

8. K. Tanigaki, Y. Ohnishi, and S. Fujiwara, "Polymers in Electronics," ACS Symposium Series 242, T. Davidson, Ed., The Amrican Chemical Society, Washington, D. C., 1984, pp 177-189.

9. J. S. Greeneich, J. Electrochem. Soc., 121, 1669 (1974).

10. J. S. Greeneich, J. Electrochem. Soc., 122, 970 (1975).

11. F. A. Bovey and G. V. D. Tiers, J. Polym. Sci., 44, 173 (1960).

12. K. Ito, S. Iwase, K. Umehara, and Y. Yamashita, Kogyo Kagaku Zasshi, 70, 993 (1967); J. Macromol. Sci., Chem., A1; 891 (1967).

13. S. Brownstein, S. Bywater, and D. J. Worsfold, Makromol. Chem., 48, 127 (1961).

14. G. N. Taylor, personal communication, to have been published in the June 1984 issue of solid state technology.

15. V. K. Sharma, R. A. Pethrick, and S. Affrossman, Polymer, 23, 1732 (1982).

16. H. Hiraoka, IBM J. Res. Develop., 21, 121 (1977).

17. J. Guillet; "Polymer Photophysics and Photochemistry," Cambridge Univ. Press, London, 1985, p 362.

18. A. M. Kotliar, J. Appl. Polym. Sci., 2, 134 (1959).

19. N. Ueno, W. Gädeke, E. E. Koch, R. Engelhardt, and R. Dudde, J. Electron. Spectr. Relat. Phenom., 36, 143 (1985)

20. K. Harada, J. Appl. Polym. Sci., 26, 1961 (1981).

21. N. Ueno, S. Konishi, K. Tanimoto, and K. Sugita, Jpn. J. Appl. Phys., 20, L709 (1981).

22. K. Sugita, N. Ueno, S. Konishi, and Y. Suzuki, Photogr. Sci. Eng., 27, 146 (1983).

23. K. Sugita, N. Ueno, and S: Namekata, to be published.

24. E. Dans and J. Guillet, Macromolecules, 6, 230 (1973). 